\title{
Mindsponge Mechanism
}

Subjects: Sociology | Psychology, Psychoanalysis | Business

Contributor: Minh-Hoang Nguyen, Quan-Hoang Vuong, Ho Manh Toan, Tam-Tri Le

The mindsponge mechanism (mindsponge framework, mindsponge concept, or mindsponge process) provides a way to explain how and why an individual observes and ejects cultural values conditional on the external setting. The term "mindsponge" derives from the metaphor that the mind is analogized to a sponge that squeezes out unsuitable values and absorbs new ones compatible with its core value. Thanks to the complexity and well-structuring, the mechanism has been used to develop various concepts in multiple disciplines. One such concept is "cultural additivity" (https://www.nature.com/articles/s41599-018-0189-2). Recently, the mindsponge mechanism has been developed into mindsponge theory based on various evidence from natural sciences.

mindsponge mechanism additivity psychology cultural values multi-filtering information process psycho-religious mechanism

\section{| Introduction}

No matter the Earth is flat or spiky, globalization has passed the point of no return. In a fastchanging globalized world, increasing movements and exchanges between different regions, cultures, and populations worldwide are undeniable. Such movements and exchanges result in acculturation processes all over the world.

The mindsponge mechanism is proposed by Vuong Quan Hoang \& Nancy K. Napier [1]][2] for explaining how and why an individual "learns and unlearns" cultural values, which helps us better understand the complexity of acculturation in a global context. Originally, the framework was used to study acculturation phenomena and the development of global mindset at individual and organizational levels by answering the question: "What is the determining mechanism of absorbing and ejecting cultural core values in a mindset?". More specifically, it demonstrates a global mindset as a dynamic process of inducting and expelling socio-cultural values. Through this process, executives, managers, and corporations could replace inappropriate values with new values that help them adapt to multicultural and global settings ${ }^{[3]}$, eventually improving their happiness at work $[\underline{4}]$.

Recently, the mindsponge mechanism has been developed into mindsponge theory based on various evidence from natural sciences $[\underline{5}]$.

\section{| Main components}

The conceptual diagram of the mindsponge framework consists of five components: 1) mindset, 2) comfort zone, 3) multi-filtering system, 4) cultural and ideological setting, and 5) cultural values (see Figure 1). Such components and their connections are constructed by referring to prior prominent theories and models: self-affirmation theory, 3D multi-filtering process, information processing model, inductive attitude, and model of acculturation. 


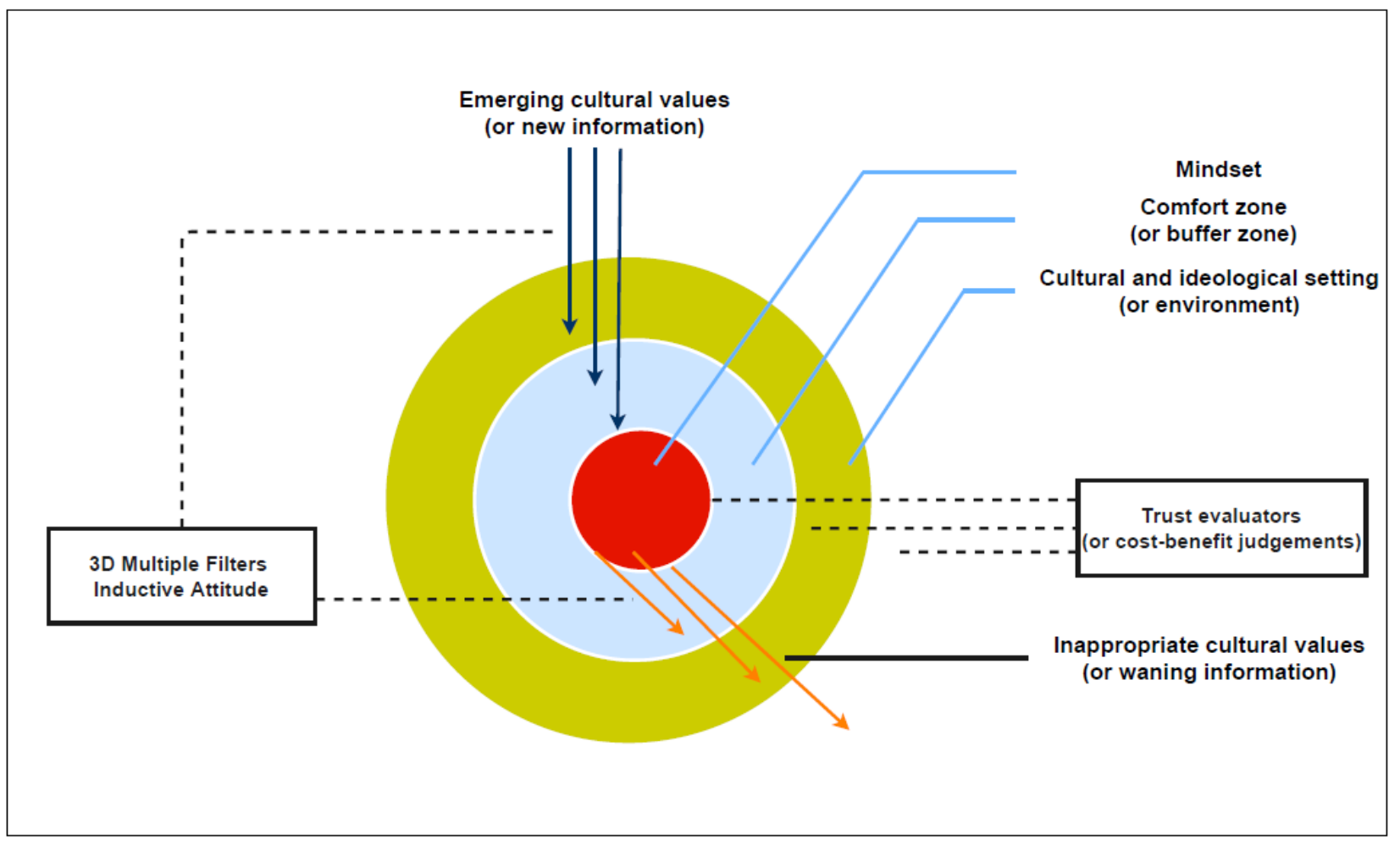

Figure 1: The mindsponge mechanism. Reproduced from Vuong and Napier.

The framework is constructed assuming that every person has a mindset, which is a non-empty set of core cultural values or beliefs that are central to individual identity []. The mindset is demonstrated by the red nucleus located in the middle of the diagram. An individual uses the core values as benchmarks explicitly and implicitly, especially when they need judgment on the usefulness and appropriateness of emerging cultural values (or information) and when they need to make decisions and responses. This function of the mindset gives the individual a selfprotection mechanism of their "self", which is analogous to the self-affirmation theory. However, the core values can still be changed by attacks of emerging values and clashes with other core values

The mindset is surrounded by a light blue circle, which is called the comfort zone. Values that are close and supportive to the mindset are constituting this zone. The Comfort zone is a buffer playing two functions. First, the comfort zone protects the mindset from external shocks - for instance, cultural shocks. Second, the comfort zone helps filter and evaluate information regarding the appropriateness and usefulness of any emerging value.

When information or cultural values enter the comfort zone from the environment, they also enter the multi-filtering system. The 3D multiple filters inductive attitude and trust evaluators are two fundamental parts of the system. The 3D multiple filters play two roles: 1) integration and 2) differentiation. While integration synthesizes and incorporates information and value that are compatible with the core values, differentiation measures the difference between the emerging and existing values to assess the cost and benefit of accepting or rejecting the emerging values (or even replacing old core values with the new ones). The closer the new values get to the mindset, the more stringent evaluation they receive.

The blue arrows represent the inflow of the entering information or values, whereas the orange arrows indicate the outflow of inappropriate information or values. Both flows are driven by the 3D multi-filtering process ${ }^{[\underline{ }]}$ and the inductive attitude ${ }^{[8]}$. Inductive attitude and the 3D multi-filter process facilitate trust-building exercises for comfort zone values. By reaching the critical mass, the emerging value is allowed to enter the core mindset by the trust evaluator. In reverse, a core value can lose its trust level then the evaluator forces it out of the nucleus. The trust evaluator, 
which can be understood as the cost-benefit judgment of the individual, plays the guarding role during the whole filtering process, at any place and any time.

Based on the information processing mechanism of the mindsponge, there can be two extremes. The first case is when an individual completely ignores the emerging values from the surrounding environment. This is because the 3D multi-filtering process does not work, and the individual's "radar" is not turned on, making the individual not receptive to the information from the environment. Another reason lies in the cost of absorbing new values or information. In other words, the individual perceives incorporating new values or information into the mind to be too expensive, so the existing set of values is kept unchanged. The second extreme case is when the individual is so eager to change that they can easily replace their existing core values or beliefs with the new ones. This situation is attributable to the negligent trust evaluators, making the individual perceive the cost to change relatively low.

\section{| A simplified mindsponge information process}

The flow of information in a simplified mindsponge process comprises of the following steps.

Step 1: Information from the external environment or internal memory enters the buffer zone. Here the information is evaluated by the filtering system.

Step 2: The information's value is subjectively judged based on its perceived costs and benefits. If the perceived benefit is greater than its perceived costs, then the information's value is deemed positive, and vice versa. Trusted values from the mindset (stored in memory and retrieved when needed) are used as references for the judgments (related trusted values are connected and compared to the currently evaluated information).

Acceptance: The information is accepted if the information's value is positive.

Rejection: The information is rejected if the information's value is negative.

Step 3: If the information is accepted, it can move into the mindset and become a new trusted value. This new trusted value can be used as a reference for future evaluations of information related to it. If the accepted information directly corresponds to a behavior (whether mental or physical), that behavior will be carried out.

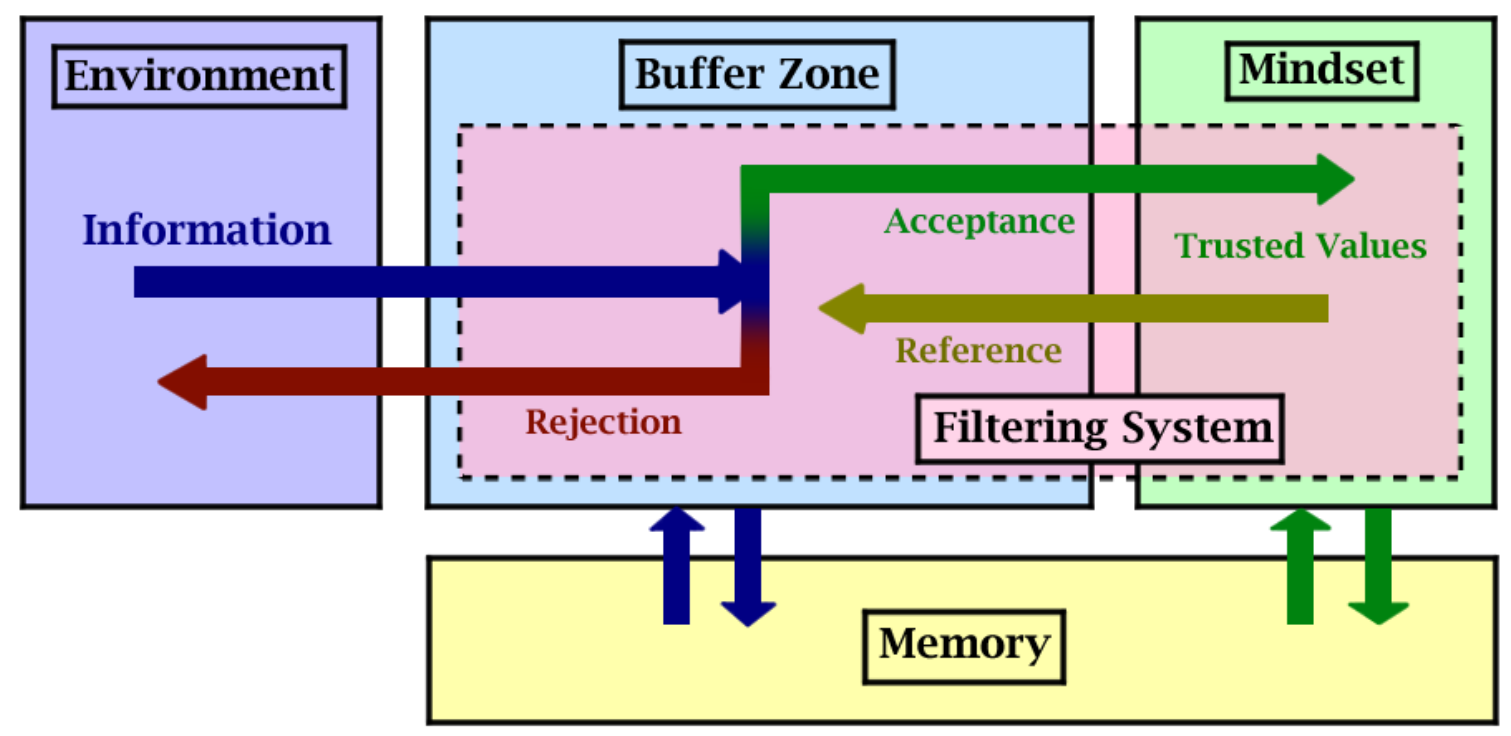

Figure 2: A simplified mindsponge process. 


\section{Main characteristics}

\section{Information generating}

Processing information also means new information is generated. In the evaluating processes, the evaluated information interacts with other information used as references and changes its value. Since the subjective values of information are created from connecting and comparing them with other trusted values, any thinking activity causes the processed values to become different (to some degree) from their original input value. The mindsponge process employs the principles of induction and innovation, like the serendipity process [9]. It can also be said that information processing is itself information generating, with its properties and function deeply intertwined. Even remembering past events (a simple, quick re-evaluation of trusted perceived 'facts') can cause changes in the recalled information's content and attitude toward it over time. The information-generating aspect can also be observed on a collective level; for example, when new cultural values are added, adopted, and mixed with the existing cultural values of a community, new and unique local values can be created within that community.

\section{Trust: the 'priority pass'}

In the Mindsponge framework, trust toward a set or source of information (a group of information sharing some similar properties) is the belief about its reliability or generalized value. Trust is often applied to a source of information, such as a family member, intimate partner, or a person of authority (e.g. governmental agent) or expertise (e.g. scientist). It can also be applied to an information set (e.g. ideology, doctrine, group identity).

Trust acts as a 'priority pass' that quickens the evaluation process. The trust value is either negative (distrusted) or positive (trusted); if the value is neutral, it can be said that there is no existing trust value (indifferent). The trust value is also put on a gradient of belief strength (degree of trust). A positive trust value helps shift the perceived value of related information to be more beneficial and vice versa. For example, if a daughter trusts her father, she will find it easier to accept information from him than from a neutral stranger. However, if she distrusts him, the effect will be the opposite. On a collective level, generalized trust (trusting other people in the society) closely goes with social connectedness [10]. The 'priority pass' effect of social connectedness was shown to influence the receptibility of specific information groups [11][12]. Trust can be considered a special type of trusted value from the mindset which is used as a group reference in the cost-benefit judgment.

Since utilizing trusts (attaching a general added value to a group of information), the mind can save more energy and time than evaluating new information from scratch. The information needs to be previously accepted and integrated into the mindset before it can function as a priority pass. In other words, before trusting a certain source, the value of 'this source is reliable' must first be evaluated and become trusted (the process of trust-building). The opposite direction is distrustbuilding. Once a general perceived value of the group has been developed, the other information belonging to that same group is expected to have a similar value.

\section{Updating}

The mindset is always changing because the Mindsponge processes do not stop as long as the mind still functions normally. Accepting beneficial new information and rejecting waning old information cause changes in the mindset's content. The set of trusted values need to change for the mind to adapt to its constantly changing living environment. Because the mindset determines the operation of the filtering system, changes in mindset also lead to changes in the evaluation of new information. A mutually interacting circular cause-effect relationship between the mindset and the filtering system updates the whole mindsponge apparatus. This updating manner can 
normally be observed in our daily life (individual level) and throughout human history (collective level). For example, a person who hated broccoli as a child turns to enjoy it when they grow older; a former society with widespread racial discrimination turns into a modern society that respects and embraces racial equity, etc.

Belief reinforcement is an important aspect of the Mindsponge updating manner. A value accepted into the mindset will be used as a reference for subsequent evaluations of related information, thus increases the similar information's perceived value and make acceptance easier (and vice versa for information-carrying opposite values). The subsequent acceptance or rejection reinforces the trusted value in its respective direction. For example, a person who believes that lions are vicious creatures will find it easy to believe the news about a recent lion attack. This new information also reinforces that person's negative view of lions. By contrast, that person finds it hard to believe information about docile lions. If the information carries a value opposite to the trusted ones with enough impact, it may be accepted instead, and the direction of belief will be shifted; for example: hypothetically, somehow lions were genetically modified to become gentle vegetarians, people would gradually start to believe that they are not dangerous.

\section{| Applications}

As a conceptual framework for information processing, the mindsponge concept has been applied in various fields of social sciences. It is often used for studying and explaining the cultivation

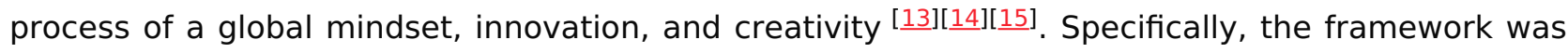
used to design the i2Metrix survey, which measures Vietnamese leading businesses' inclusive corporate innovation capacity through ten dimensions [16]. Among those dimensions, the Mindsponge dimension focuses specifically on the ability to absorb and integrate emerging cultural values into the corporate mindset for innovative change and creative performance. Due to the ability to demonstrate the dynamic process of new-value absorption and inappropriate-value replacement at the individual level, the mindsponge concept is recommended as a promising tool to explore whether the interaction between expatriates' personality and experience of cultural differences could influence creativity $[\underline{17]}$. Outcomes of the mindsponge processes are also found to be the determinants of entrepreneurs' decisions to start a business [르. The mechanism is also used to explain how Covid-19 vaccines have been produced within a limited time ${ }^{[\underline{19}]}$.

The mindsponge framework could explain many socio-cultural issues. Besides the acculturation process [20][21], it is also used in conjunction with the concept of cultural additivity in examining the acceptance and rejection of religious values in spiritual healing [22]. The study shows that cultural additivity and the mindsponge mechanism allow the additions of new and contradicting values, which makes the adaptation to spiritual practices and the reception of different traditions and values more applicable. Based on the mechanism of Mindsponge, Ärleskog et al. suggested that building a structured reflection model to raise awareness constantly might change the healthcare users' perspective, which consequently helps improve the co-production practices [2ㄱ].

The complexity and dynamic of mindsponge are also useful in studying mental health and psychological issues, like how depressive disorders are attributable to acculturative stress [24][르][드]. More specifically, individuals living in a new environment with different cultural settings need to adapt and establish their social networks. Making new friends in a new cultural environment is equivalent to accepting new cultural values, so the filtering process will be performed to evaluate whether to trust the new friends/values or not. During this process, if the individual trusts the new friends/values, they will let the friends/values come closer to themselves/mindset. In contrast, if conflicts happen between the new friends/values and the individuals/mindsets, the individual's filter will push the new values away from the mindset, creating a larger emotional distance between the individual/mindset and the new friends/values. Such distance might result in loneliness which is one of the primary predictors of depression. 
The mindsponge framework was recently expanded to be the theoretical foundation for investigating how the mind processes suicide-related information [11]. The psychological mechanism of the formation or cessation of suicidal thoughts focuses on two principles in the framework: information accessibility (the availability of information sources and the subjective perception about them) and information filtering (with cost-benefit judgments) (see Figure 3). The information process of Mindsponge also enabled the exploration into the psycho-religious mechanism of suicidal ideation and suicide attack ${ }^{[12]}$, by further integrating interactions with factors of religious beliefs as well as hostile environmental context.

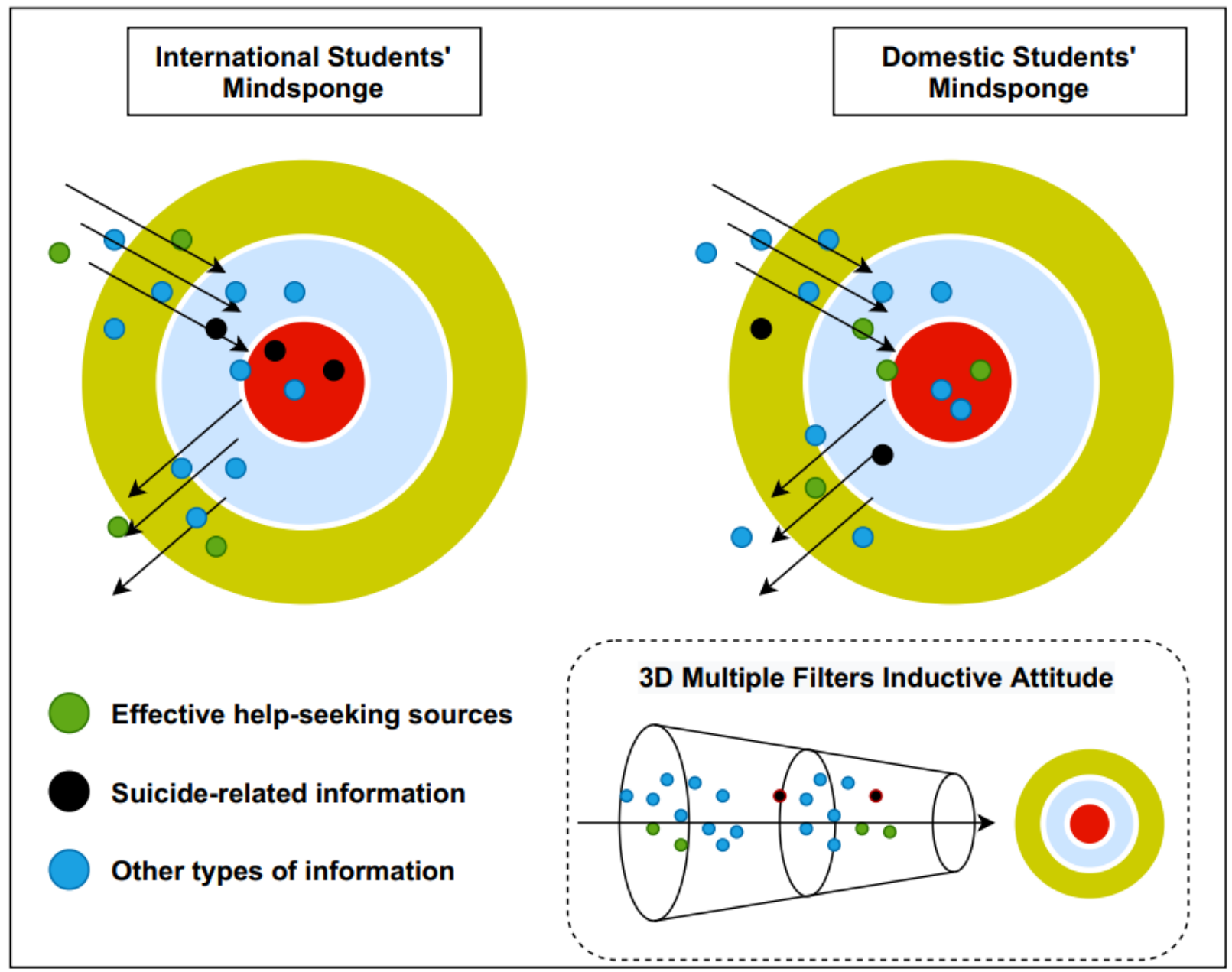

Figure 3: The mindsponge-based suicidal ideation mechanism

In a study about children's book reading interest [27], a similar approach was used to examine the mechanism of reading interest in low- and high-achieving students through different thinking pathways. Here, the Mindsponge aspect of cost-benefit judgments helps predict and explain how the sense of autonomy influences children's attitudes toward their sources of information. This study and other previous psychological research also showed the great compatibility of utilizing the Bayesian analysis with Mindsponge processes. The approach is called Bayesian Mindsponge

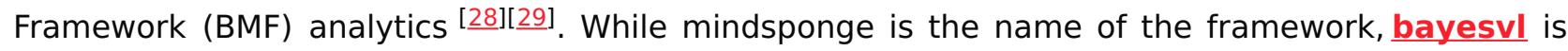
the name of the software that performs the analysis of Bayesian models [30][31][32].

The mindsponge mechanism was foundational for establishing the new theory of serendipity. Based on the mechanism, the new theory of serendipity explains how serendipity happens under the information processing perspective and suggests that serendipity is a survival skill that can be cultivated, but not "luck" or "fate" [3]. Mindsponge is also a cornerstone of the serendipitymindsponge-3D knowledge management framework used to explain the information processes of the development, production, and distribution of COVID-19 vaccines [34]. Another crucial application of the mindsponge mechanism was examining the western ideological homogeneity 
issue in entrepreneurial finance research. By treating highly cited papers as the research field's mindset and the publishing system as the ideological value filters, the authors created a new approach of using bibliometric analyses (the Y-index and social network analysis) for assessing the state of ideological dominance and ideological heterogeneity tolerance within a research field [35].

\section{References}

1. Vuong QH. (2016). Global mindset as the integration of emerging socio-cultural values through mindsponge processes: A transition economy perspective. In J. Kuada (Ed.), Global Mindsets: Ex ploration and Perspectives (pp. 123-140). New York: Routledge.

2. Vuong QH, Napier NK. (2015). Acculturation and global mindsponge: An emerging market persp ective. International Journal of Intercultural Relations, 49, 354-367.

https://doi.org/10.1016/j.ijintrel.2015.06.003

3. Kuada J. (2016). Mindsets and global organizational strategies. In J. Kuada (Ed.), Global Mindsets: Exploration and Perspectives (pp. 1-7). New York: Routledge.

4. Basinska BA, Rozkwitalska M. (2020). Psychological capital and happiness at work: The mediatin $\mathrm{g}$ role of employee thriving in multinational corporations. Current Psychology. https://doi.org/10. 1007/s12144-019-00598-y

5. Quan-Hoang Vuong. (2022). Mindsponge Theory. AISDL. https://books.google.com/books?id=OSi GEAAAQBAJ

6. Correll J, Spencer SJ, Zanna MP.(2004). An affirmed self and an openmind: Self-affirmation and S ensitivity to argument strength. Journal of Experimental Social Psychology, 40, 350-356. https:// doi.org/10.1016/j.jesp.2003.07.001

7. Vuong QH, Napier NK. (2015). Making creativity: the value of multiple filters in the innovation pr ocess. International Journal of Transitions and Innovation Systems, 3(4), 294. https://doi.org/10.1 504/IJTIS.2014.068306

8. Pólya G. (1954). Induction and analogy in mathematics: Mathematics and plausible reasoning. P rinceton, NJ: Princeton University Press

9. Napier NK, Vuong QH. (2013) 'Serendipity as a strategic advantage', in Wilkinson, T. (Ed.): Strat egic Management in the 21st Century, Vol. 1, pp.175-199, Praeger, Westport, CT.

10. Sturgis P, Patulny R, Allum N, Buscha F. (2015). Social connectedness and generalized trust: a lo ngitudinal perspective. In Yaojun Li (Ed.), Handbook of Research Methods and Applications in So cial Capital (pp. 76-90). Edward Elgar Publishing Limited.

11. Nguyen MH, Le TT, Nguyen HKT, Ho MT, Nguyen HTT, Vuong QH. (2021). Alice in Suicideland: Ex ploring the suicidal ideation mechanism through the sense of connectedness and help-seeking $b$ ehaviors. International Journal of Environmental Research and Public Health, 18(7), 3681.

https://doi.org/10.3390/ijerph18073681

12. Vuong QH, Nguyen MH, Le TT. (2021). A mindsponge-based investigation into the psycho-religio us mechanism behind suicide attacks. Warsaw, Poland: De Gruyter.

13. Donato RA. (2019). Global mindset strategies for increasing hotels' performance. (Doctor of Busi ness Administration), Walden University, Walden Dissertations and Doctoral Studies Retrieved fr om https://scholarworks.waldenu.edu/cgi/viewcontent.cgi?article $=8062 \&$ context $=$ dissertations

14. Pak YS, Hsu MY. (2018). An empirical study on the development of global mindset through learni ng. Korean Management Review, 47(2), 481-503.

15. Wurster S. (2021). Creating a circular economy in the automotive industry: The contribution of c ombining crowdsourcing and Delphi research. Sustainability, 13(12), 6762. https://doi.org/10.33 
16. Vuong QH, Napier NK, Vu KH, Nguyen MC, Tran TD. (2014). Measuring corporate innovation capa city: Experience and implications from i2Metrix implementation in Vietnam. ASEAN Journal of Ma nagement and Innovation, 1(1), 1-17.

17. Stoermer S, Lauring J, Selmer J. (2020). The effects of positive affectivity on expatriate creativity and perceived performance: what is the role of perceived cultural novelty? Internation al Journal of Intercultural Relations, 79, 155-164. https://doi.org/10.1016/j.ijintrel.2020.09.001

18. Vuong QH. (2016). Impacts of geographical locations and sociocultural traits on the Vietnamese entrepreneurship. SpringerPlus, 5, 1189. https://doi.org/10.1186/s40064-016-2850-9

19. Vuong QH, et al. (2022). Covid-19 vaccines production and societal immunization under the sere ndipity-mindsponge-3D knowledge management theory and conceptual framework. Humanities and Social Sciences Communications, 9, 22. https://www.nature.com/articles/s41599-022-01034 $-6$

20. Bărbulescu O, Tecău AS, Munteanu D, Constantin CP. (2021). Innovation of startups, the key to u nlocking post-crisis sustainable growth in Romanian entrepreneurial ecosystem. Sustainability, 1 3(2), 671. https://doi.org/10.3390/su13020671

21. Verrips A, Schoonewelle L. (2019). The employee's journey to a new organisational culture: How employees experience the acculturation process post-acquisition. (Master Degree), Lund Univer sity, PhilPapers. Retrieved from https://philpapers.org/archive/VERTEJ.pdf

22. El Fakahany, Sohayla. (2021). Meanings of mindfulness and spiritual awakening: Affliction and $h$ olistic healing in contemporary Cairo. (Master's Thesis), American University in Cairo, AUC Know ledge Fountain. Retrieved from https://fount.aucegypt.edu/etds/1627/

23. Ärleskog C, Vackerberg N, Andersson A-C. (2021). Balancing power in co-production: introducing a reflection model. Humanities and Social Sciences Communications, 8, 108. https://doi.org/10.1 057/s41599-021-00790-1

24. Nguyen MH, Le TT, Meirmanov S. (2019). Depression, acculturative stress, and social connected ness among international university students in Japan: A statistical investigation. Sustainability, 11(3), 878. https://doi.org/10.3390/su11030878

25. Nguyen MH, Serik M, Vuong TT, Ho MT. (2019). Internationalization and its discontents: Help-see king behaviors of students in a multicultural environment regarding acculturative stress and de pression. Sustainability, 11(3), 878. https://doi.org/10.3390/su11071865

26. Ranizal M, Adli M, Zabidi W, Qatrunnisa W, Shariff M, Aziera S, Jackleyn S, Amir S, Amiera S. (201 9). Depression among university students. e-Journal of Media \& Society, 2.

27. Vuong QH, Nguyen MH, Le TT. (2021). Home scholarly culture, book selection reason, and acade mic performance: Pathways to book reading interest among secondary school students. Europe an Journal of Investigation in Health, Psychology and Education, 11(2), 468-495. https://doi.org/10.3390/ejihpe11020034

28. Nguyen MH, La VP, Le TT, Vuong QH. Introduction to Bayesian Mindsponge Framework analytics: An innovative method for social and psychological research. MethodsX, 9, 101808. https://doi.or g/10.1016/j.mex.2022.101808

29. Vuong QH, Nguyen MH, La VP. (2022). The mindsponge and BMF analytics for innovative thinkin $\mathrm{g}$ in social sciences and humanities. Berlin, Germany: De Gruyter. ISBN (PDF): 978-83-67405-119; ISBN (hardcover): 978-83-67405-10-2. doi:10.2478/9788367405119

30. Vuong QH, La VP, Nguyen MH, Ho MT, Tran T, Ho MT. (2020). Bayesian analysis for social data: A step-by-step protocol and interpretation. MethodsX, 7, 100924. https://doi.org/10.1016/j.mex.20 20.100924

31. Vuong QH, La VP, Nguyen MH, Ho MT, Ho MT, Mantello P. (2020). Improving Bayesian statistics u 
nderstanding in the age of Big Data with the bayesvl R package. Software Impacts, 4, 100016. $\mathrm{h}$ ttps://doi.org/10.1016/j.simpa.2020.100016

32. La VP, Vuong QH. (2019). bayesvl: Visually learning the graphical structure of Bayesian network $s$ and performing MCMC with 'Stan'. The Comprehensive R Archive Network (CRAN). Retrieved fr om: https://cran.r-project.org/web/packages/bayesvl/index.html

33. Vuong QH. (2022). A New Theory of Serendipity: Nature, Emergence and Mechanism. Berlin, Ger many: De Gruyter GmbH. ISBN-13: 9788366675865 . doi:10.2478/9788366675865

34. Vuong QH, et al. (2022). Covid-19 vaccines production and societal immunization under the sere ndipity-mindsponge-3D knowledge management theory and conceptual framework. Humanities and Social Sciences Communications, 9, 22. https://www.nature.com/articles/s41599-022-01034 $-6$

35. Vuong QH, Nguyen TTH, Pham TH, Ho MT, Nguyen MH. (2021). Assessing the ideological homog eneity in entrepreneurial finance research by highly cited publications. Humanities and Social S ciences Communications, 8, 110. https://doi.org/10.1057/s41599-021-00788-9

36. Vuong $\mathrm{QH}$, et al. (2022). Covid-19 vaccines production and societal immunization under the sere ndipity-mindsponge-3D knowledge management theory and conceptual framework. Humanities and Social Sciences Communications, 9, 22. https://www.nature.com/articles/s41599-022-01034 $-6$

Retrieved from https://encyclopedia.pub/entry/6488 